\title{
NUMERICAL ANALYSIS FOR TWO PHASE FLOW DISTRIBUTION HEADERS IN HEAT EXCHANGERS
}

\author{
B.Babu ${ }^{1}$, Florence. ${ }^{2}$, M.Punithavalli ${ }^{3}$, B.R.Rohit ${ }^{4}$ \\ ${ }^{1}$ Assistant professor, Department of mechanical engineering, Rathinam technical campus, Coimbatore \\ ${ }^{2}$ Assistant professor, Department of mechanical engineering, Rathinam technical campus, Coimbatore \\ ${ }^{3}$ Assistant professor, Department of mechanical engineering, Rathinam technical campus, Coimbatore \\ ${ }^{4}$ Assistant professor, Department of mechanical engineering, Rathinam technical campus, Coimbatore
}

\begin{abstract}
A flow header having number of multiple small branch pipes are commonly used in heat exchangers and boilers. In beginning the headers were designed based on the assumption that the fluid distribute equally to all lateral pipes. In practical situation the flow is not uniform and equal in all lateral pipes. Mal distribution of flow in heat exchangers significantly affects their performance. Non-uniform flow distribution from header to the branch pipes in a flow system will lead to $25 \%$ decrease in effectiveness of a cross flow heat exchanger. Mal distribution of flow in the header is influenced by the geometric parameters and operating conditions of the header. In this work the flow distribution among the branch pipes of dividing flow header system is analyzed for two phase flow condition. In the two phase flow condition, the effect of change in geometric cross sectional shape of the header (circular, square), inlet flow velocities are varied to find the flow mal distribution through the lateral pipes are investigated with the use of Computational Fluid Dynamics software.
\end{abstract}

Keywords: circular, square headers and Computational Fluid Dynamics software. (CFD)

\section{INTRODUCTION}

\subsection{General}

Flow distribution headers are an integral part of many engineering applications such as heat exchangers, air conditioning systems etc. These headers involve redistributing the internal flow stream into several passages. They are designed based on the common assumption that through these distribution manifolds, flow is distributed uniformly. In practical situations, transition can occur anywhere along the flow length inducing flow maldistribution and a reduction in the desired performance of the equipment. The heat exchanger headers are not an exception and their design is based on the assumption of equal flow rate in all the channels. The number of influencing variables like area ratio, lateral pipe resistance, No of lateral pipes, pitch distance etc., and this affects the thermal and hydraulic performances of the heat exchanger. The design of these heat exchangers, for the sake of compactness and also for its functioning necessitates a branching of the internal fluid flow into several parts. The uniform flow through each branch without any flow maldistribution is desired for uniform temperature variation over the different branches.

\subsection{Flow Maldistribution}

Flow mal distribution induced by

1. Geometry of Heat exchanger

2. Operating condition of Heat exchanger

\subsection{Geometry Induced Flow Maldistribution}

One class of flow mal distribution, which is a result of geometrically non ideal fluid flow passages or non ideal heat exchanger inlet/outlet header design, is referred to as geometry induced flow mal distribution. This is peculiar to a particular heat exchanger in question and cannot be influenced significantly by modifying operating conditions. The most important causes of flow non-uniformities can be three groups of mal distribution effects:

i. Gross flow mal distribution

ii. Passage to Passage flow mal distribution

iii. Manifold induced flow mal distribution

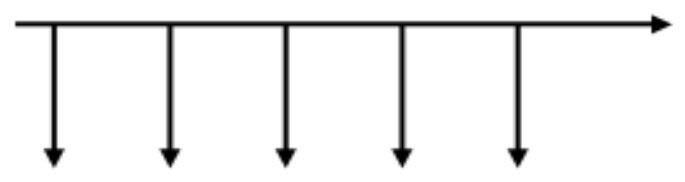

Fig 1.1 Dividing flow header

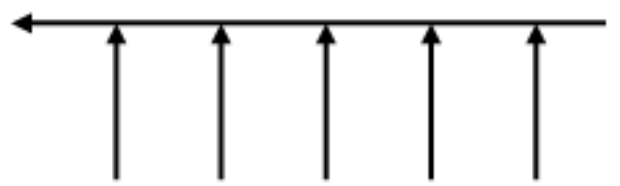

Fig 1.2 Combining flow header 


\section{PROBLEM DEFINITION}

In flow headers it has been found out that maldistribution is very closely related to the geometrical and operating conditions of the header. Studies reveal that to geometrical parameters such as, cross sectional shape of the header, lateral pipe spacing, lateral pipe height, No of pipes, inlet flow velocity etc. But, fabricating the setup and conducting several experiments is a tedious task. So the experiments have been performed for two combination of influencing parameters and are validated with CFD software. The results are found to have close correlation. Based on this concept a Numerical study of flow distribution for Dividing Headers has to be carried out and the degree to which all these parameters affect flow distribution have to be found out.

\section{EXPRIMENTAL WORK}

\subsection{Results Extraction Procedure}

The basic equations such as turbulent equation if the flow is turbulent were to be chosen and the values of the boundaries such as velocity inlet at the header, operating pressure etc. were specified according to each case. The fluid (waterliquid) was selected and the fluid properties such as viscosity, density were defined.

The solution control parameters were adjusted and the solver was initialized and iterated till the solution was converged.

With the use of surface integral option in the fluent the volume flow rate of each pipe outlet is calculated directly. Then the maldistribution value of the header is calculated by

$$
m=\frac{m_{i}-m_{c v}}{m_{c v}}---(3)
$$

Where $m_{i}$ is the Mass flow rate through $1^{\text {st }}$ pipe and $m_{a v}$ is the flow in one lateral pipe for a completely uniform distribution

The pressure distribution inside the header is another important factor that affects the maldistribution value. The iso surface option in the software is used obtained the pressure distribution inside the header. A line was created at the center of the model by specifying the X,Y,Z coordinates.

\section{RESULTS AND DISCUSSION}

\subsection{Cfd Validation Procedure}

Any analysis needs its results to be validated for genuineness of the analysis procedures. This is due to the fact that, CFD if used with wrong inputs and boundary conditions can generate wrong results. The selection of computational models to be included in a particular analysis is also important. A procedure for analyzing the flow system of a dividing header is obtained. This procedure has to be cross checked before going for real analysis. From the collected literatures. Osakabe [ ] have experimentally analyzed water flow distribution in a dividing header for two phase conditions. These experimental results are considered for validation of CFD procedure.

\subsection{Experimental Setup Proposed by osakabe [1] and the cfd Model}

The length of the branch pipe was $1000 \mathrm{~mm}$. For two phase analysis water and air are supplied at velocities of $0.054 \mathrm{~m} / \mathrm{s}$ and $0.04 \mathrm{~m} / \mathrm{s}$ respectively.

In the CFD analysis, a similar model as that of the experimental setup with exact dimensions was used. A schematic diagram of the CFD model is shown in fig.4.1. All the experimental conditions were imposed without any change.

\subsubsection{Extraction of the Results}

Using the fluxes option in the software the flow rate through each pipe is calculated. From this value the dimensionless volumetric flow also calculated. Then the results are compared with experimental results.

The similar procedure is applied to validate the CFD results when the system operating at two phase condition and the results are shown in the Fig.4.1.

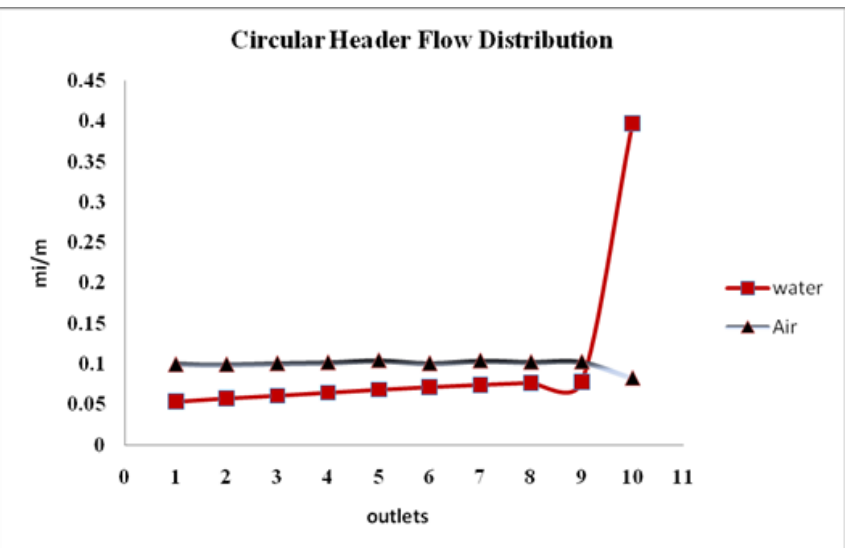

Fig.4.1. Schematic Grid Diagram of the CFD Model for the Experimental Setup Proposed By Osakabe

\subsubsection{Validation of Two Phase Flow DI}

For two phase analysis water and air are supplied at velocities of $0.054 \mathrm{~m} / \mathrm{s}$ and $0.04 \mathrm{~m} / \mathrm{s}$ respectively. The experimental and CFD results for distribution of water through the each lateral pipe are compared and shown in Fig.4.2. 


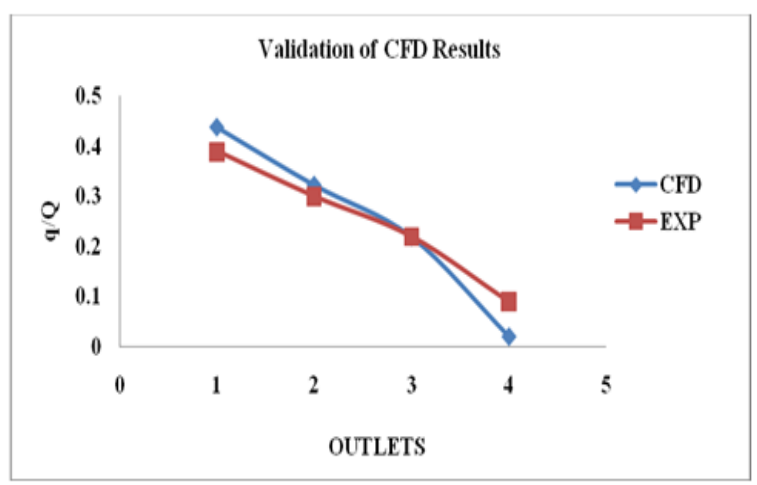

Fig 4.2: water flow distribution at $\mathrm{v}_{\mathrm{sl}}=.054 \mathrm{~m} / \mathrm{s} \& \mathrm{v}_{\mathrm{sg}}=.04 \mathrm{~m} / \mathrm{s}$

A well established step by step CFD procedure was obtained for analyzing any type of flow system. The same procedure is validated against the published experimental results. And a good agreement is obtained between the two results with an acceptable error limit. Hence this procedure can be used for analyzing the flow system of a different header configuration and operating at different operating conditions.

\subsection{Two-Phase Flow Results}

Numerical analysis is done for dividing header having 17 $\mathrm{mm}$ diameter (D) with the branch pipes of dimensions $16 \times 1.03 \times 125 \mathrm{~mm}$ respectively. The effect of flow distribution when varying the geometrical shape of the dividing header (circular, Square) is discussed.

\subsubsection{Flow Distribution in Circular Header}

In the circular header the water flow rate is maximum at $10^{\text {th }}$ pipe and minimum at $1^{\text {st }}$ pipe. From first to $9^{\text {th }}$ pipe the flow rate gradually increased. Nearly $38 \%$ of total outlet flow goes through the last pipe. The air flow distribution also shown in fig. it is in reversed manner of water flow distribution. Only minimum amount of air will flow through last pipe. The amount of non-uniformity of distribution of flow is characterized using a parameter called maldistribution $(\mathrm{m})$. From the maldistribution value we can able to find how much amount of water will over flow or under flow through the particular lateral pipe.

$$
m=\frac{m_{i}-m_{a v}}{m_{a v}}--(3)
$$

The maldistribution value for first pipe is -0.48. the negative sign indicates there is an under flow. And only 0.52 times of actual flow rate will goes through it. The last pipe vale is 3 . That means there is an over flow on the particular pipe, of amount of 3times greater than the actual flow rate.

\section{Circular Header}

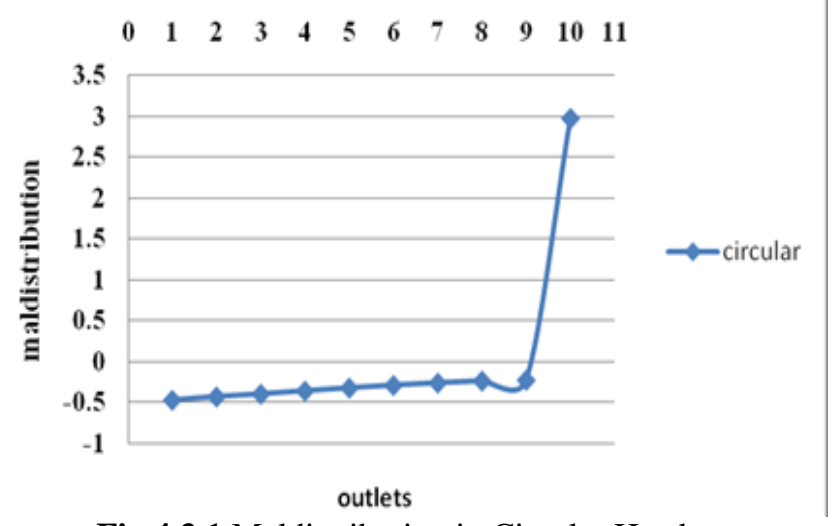

Fig 4.3.1 Maldistribution in Circular Header

\subsubsection{Flow Distribution in Square Header}

In the square header the water flow rate is maximum at $10^{\text {th }}$ pipe and minimum at $1^{\text {st }}$ pipe. From first to $9^{\text {th }}$ pipe the flow rate gradually increased. Nearly $25 \%$ of total outlet flow goes through the last pipe.

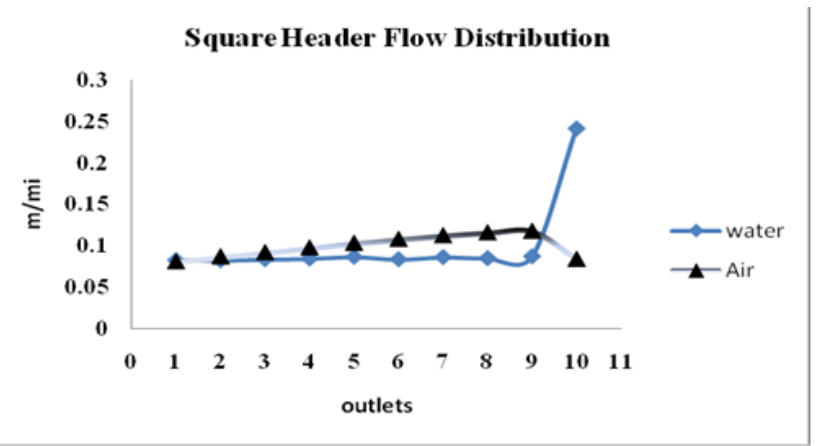

Fig 4.3.2 square header flow distribution

The air flow distribution also shown in fig. it is in reversed manner of water flow distribution. Only minimum amount of air will flow through last pipe.

\subsubsection{Flow Distribution in Square Header}

The maldistribution value for first pipe is -0.2. the negative sign indicates there is an under flow. And only 0.8 times of actual flow rate will go through it. The last pipe vale is 1.5. That means there is an over flow on the particular pipe, of amount of 1.5 times greater than the actual flow rate.

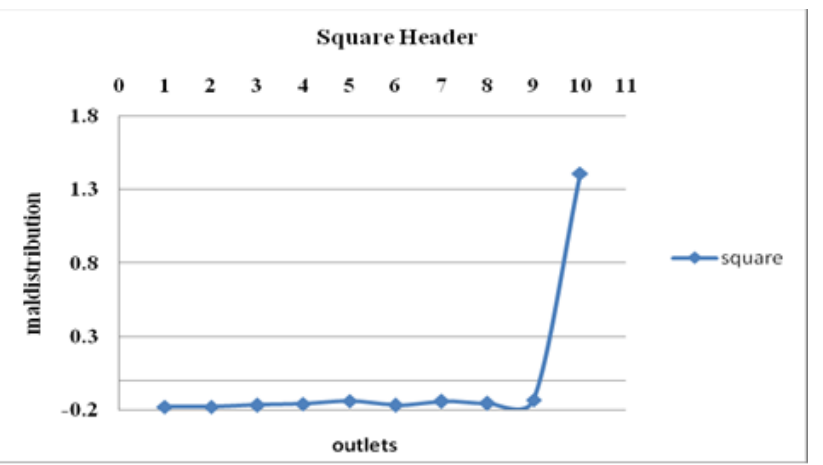

Fig 4.3.3 Flow Distribution in Square Header 


\subsection{Difference between Circular and Square}

\section{Headers}

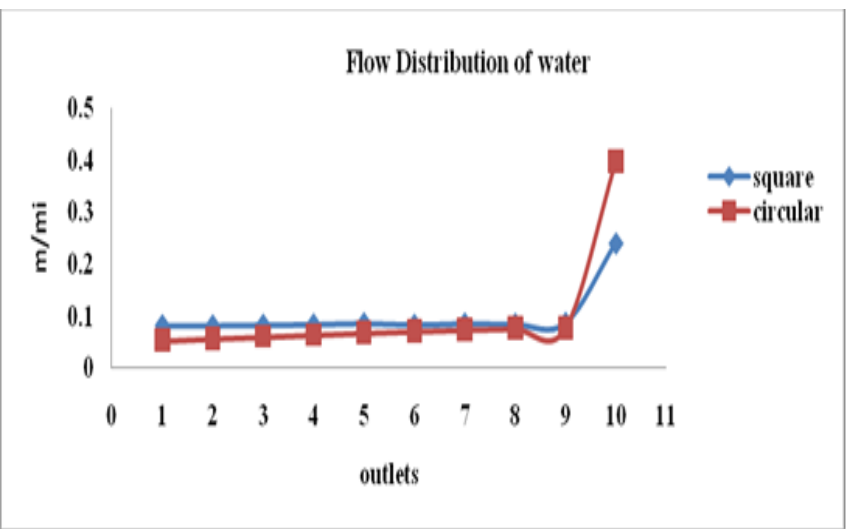

Fig 4.4: Difference between circular and square headers

When water flow rate the square headers have less uneven distribution it is shown in the fig. it is also observed from maldistribution values.

Table 4.4 comparison between circular and square headers

\begin{tabular}{c|c|c|}
\hline Pipe number & Circular & square \\
\hline 1 & -0.48 & -0.2 \\
\hline 10 & 3 & 1.5 \\
\hline
\end{tabular}

From the maldistribution values it is found that the square header shall gives the more uniform distribution when comparing the circular header.

Because it is observed that the mal distribution values are almost reduced to $50 \%$ when using the square header instead of circular header.

\subsection{Pressure Distribution inside the Header}

The predicted static pressure values along this line were plotted in graph. The graph plotted for the line drawn at the center of the header model is shown in the Fig.

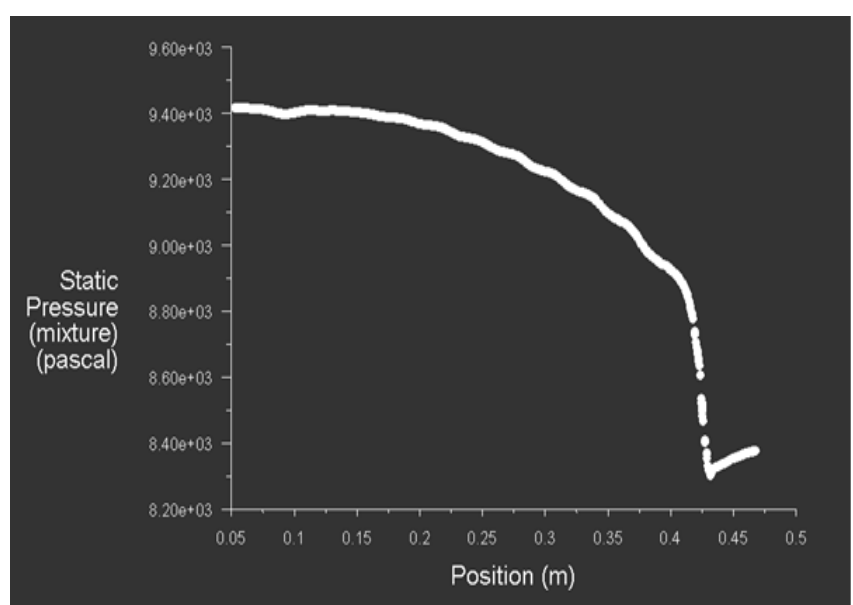

Fig 4.5 Pressure distribution inside the square header

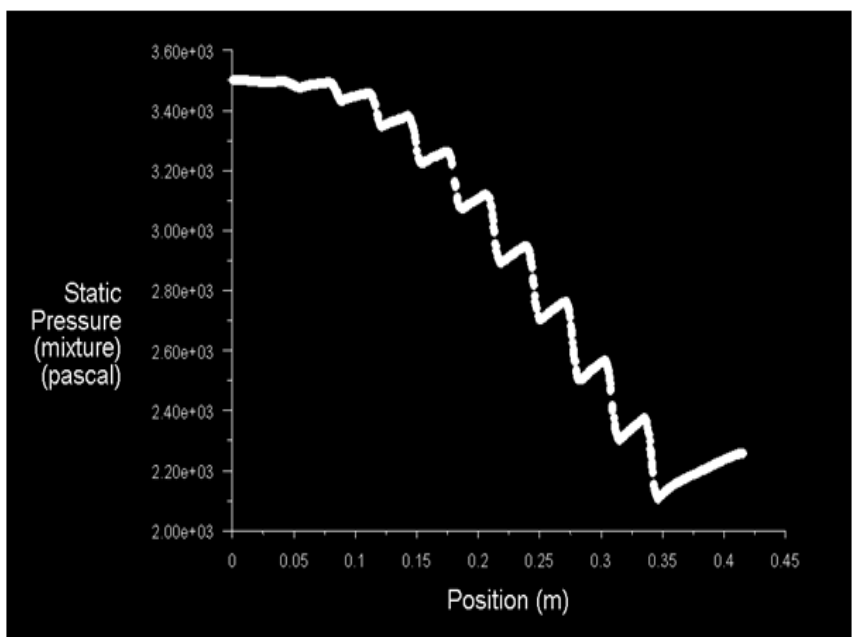

Fig 4.5.1 Pressure distribution inside the circular header

figures shows the pressure distribution inside the square and circular header respectively. Figure explains the phenomenon of pressure recovery inside the header. The decrease in pressure in the initial portion of the curves indicates the pressure drop due to the flow resistance of the pipes. Since the flow resistance in a circular header is more compared to square, the initial pressure drop is more in circular header. This is followed by rise in pressure, which is due to pressure recovery. This happens on the region where some of the fluid escapes through the outlet pipe. The net effect of pressure recovery and pressure drop causes a comparatively non-uniform pressure distribution in circular header. This picture of pressure variation cannot be brought out by an experimental analysis due to the limitation in placing pressure sensors.

\subsection{Flow Distribution in Square Header}

The fig shows the volume fraction of water inside the header. It also reflects the mass flow rate graph values. Because in the $10^{\text {th }}$ pipe only have more distribution of water.

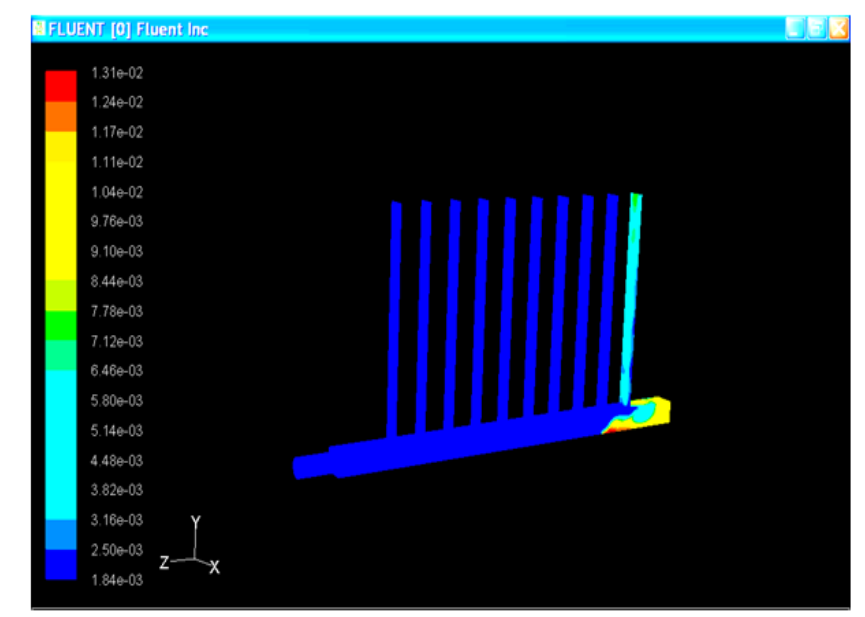

In the contour diagram also the maximum value for volume fraction observed at $10^{\text {th }}$ pipe when compare to other pipes. 


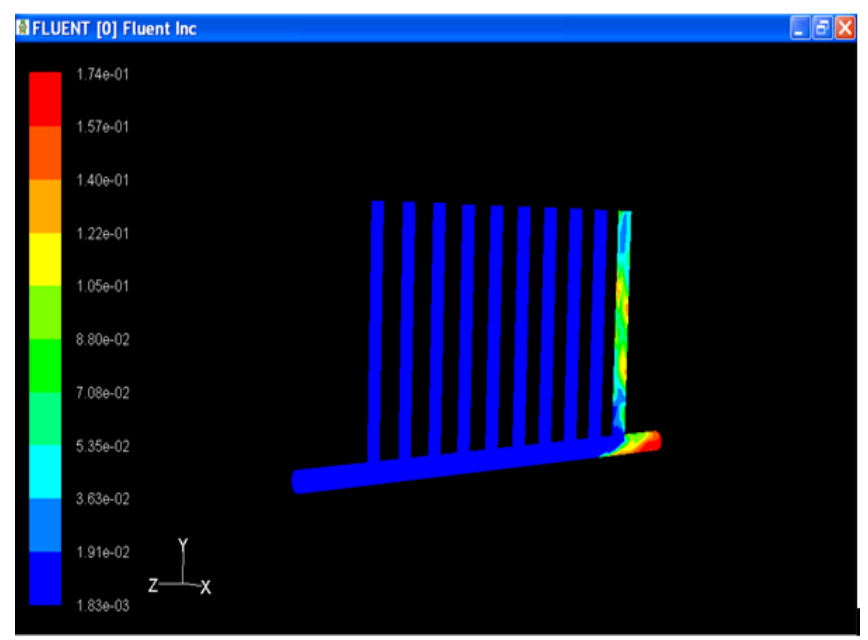

Fig 4.6 Flow distribution in square header

In the analysis we also observe that when changing the shape it only effects the flow distribution but it not effects the distribution pattern. That is distribution pattern is identical in the both the cases it is also observed when comparing the contour diagram of circular and square headers.

\section{CONCLUSION}

Header with a square cross section will give a uniform flow distribution compared to other shape. In the analysis we also observe that when changing the shape it only effects the flow distribution but it not affects the distribution pattern. When increasing the air velocity the water will flow through the rear end of the header. The results are analyzed to generate guidelines for header design. So the header shape is the important parameter which effects the flow distribution. The effect of variations on the flow distribution in a combined header needs to be studied.

\section{REFERENCES}

[1] R.C. Sachdeva, fundamental of engineering heat and mass transfer 4th edition

[2] T. Kulkarni, C.W. Bullard, K. Cho, Header design tradeoffs in microchannel evaporators, Appl. Therm. Eng. 24 (2004) 759-776.

[3] R.L. Webb, K. Chung, Two-phase flow distribution in tubes of parallel flow heat exchangers, Heat Transfer Eng. 26 (2004) 3-18.

[4] Distribution of air-water annular flow in a header of a parallel flow heat exchanger Nae-Hyun Kim SungPil Han Department of Mechanical Engineering, University of Incheon, 177 Dohwa-Dong, Nam-Gu, Incheon 402-749, Republic of Korea Two-phase flow behavior inside a header connected to multiple parallel channels Jun Kyoung Lee.

\section{BIOGRAPHIES}

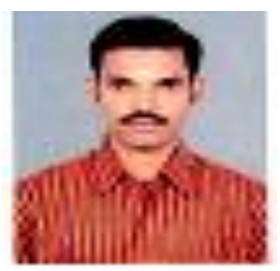

B. Babu is currently Assistant Professor in Department of Mechanical engineering, Rathinam technical campus, Coimbatore. He has published 11papers in International journals and 13 papers in national/international conference.

e-mail-babuamr11@gmail.com

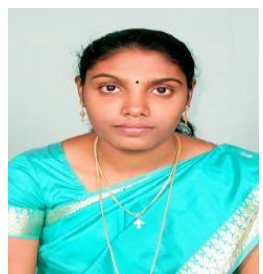

Florence.T is currently Assistant Professor in Department of Mechanical engineering, Rathinam technical campus, Coimbatore. He has published 4papersin International journals and 4papers in national/international conference.

e-mail-florencemercy2007@gmail.com

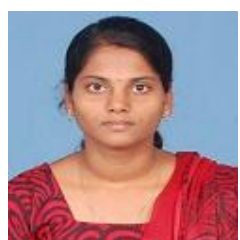

M.Punithavalli is currently Assistant Professor in Department of Mechanical engineering, Rathinam technical campus, coimbatore. He has published 2papers in International journals and 2papers in national/international conference. e-mail-puni.aero21@gmail.com

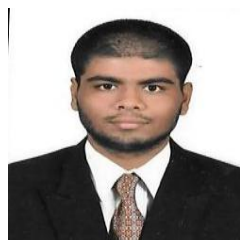

B.R.Rohit is currently Assistant Professor in Department of Mechanical engineering, Rathinam technical campus, Coimbatore. He has published 2papers in International journals and 2papers in national/international conference.

rohit.mech@rathinamcollege.com 